Research article

Open Access

\title{
Identification of women with an increased risk of developing radiation-induced breast cancer: a case only study
}

\author{
Annegien Broeks ${ }^{1}$, Linde M Braaf1, Angelina Huseinovic ${ }^{1}$, Anke Nooijen ${ }^{1}$, Jos Urbanus ${ }^{1}$, \\ Frans BL Hogervorst ${ }^{2}$, Marjanka K Schmidt ${ }^{3}$, Jan GM Klijn ${ }^{4}$, Nicola S Russell ${ }^{5}$, Flora E Van \\ Leeuwen ${ }^{3}$ and Laura J Van 't Veer ${ }^{1,2}$
}

\begin{abstract}
1Division of Experimental Therapy, The Netherlands Cancer Institute, Plesmanlaan 121, 1066 CX Amsterdam, The Netherlands 2Department of Pathology, The Netherlands Cancer Institute, Plesmanlaan 121, 1066 CX Amsterdam, The Netherlands 3Department of Epidemiology, The Netherlands Cancer Institute, Plesmanlaan 121, 1066 CX Amsterdam, The Netherlands ${ }^{4}$ Department of Medical Oncology, Dr Daniel den Hoed Cancer Centre, Groenehilledijk 301, 3075 EA, Rotterdam, The Netherlands ${ }^{5}$ Department of Radiotherapy, The Netherlands Cancer Institute, Plesmanlaan 121, 1066 CX Amsterdam, The Netherlands
\end{abstract}

Corresponding author: Laura J Van 't Veer, I.vt.veer@nki.nl

Received: 2 Oct 2006 Revisions requested: 1 Dec 2006 Revisions received: 28 Mar 2007 Accepted: 11 Apr 2007 Published: 11 Apr 2007

Breast Cancer Research 2007, 9:R26 (doi:10.1186/bcr1668)

This article is online at: http://breast-cancer-research.com/content/9/2/R26

(c) 2007 Broeks et al.; licensee BioMed Central Ltd.

This is an open access article distributed under the terms of the Creative Commons Attribution License (http://creativecommons.org/licenses/by/2.0), which permits unrestricted use, distribution, and reproduction in any medium, provided the original work is properly cited.

\begin{abstract}
Introduction Radiation exposure at a young age is one of the strongest risk factors for breast cancer. Germline mutations in genes involved in the DNA-damage repair pathway (DDRP) may render women more susceptible to radiation-induced breast cancer.

Methods We evaluated the contribution of germline mutations in the DDRP genes BRCA1, BRCA2, CHEK2 and ATM to the risk of radiation-induced contralateral breast cancer (CBC). The germline mutation frequency was assessed, in a case-only study, in women who developed a CBC after they had a first breast cancer diagnosed before the age of 50 years, and who were $(n=169)$ or were not $(n=78)$ treated with radiotherapy for their first breast tumour.
\end{abstract}

Results We identified 27 BRCA1, 5 BRCA2, 15 CHEK2 and 4 truncating $A T M$ germline mutation carriers among all CBC patients tested (21\%). The mutation frequency was $24.3 \%$ among CBC patients with a history of radiotherapy, and $12.8 \%$ among patients not irradiated for the first breast tumour (odds ratio 2.18 (95\% confidence interval 1.03 to 4.62 ); $p=0.043$ ). The association between DDRP germline mutation carriers and risk of radiation-induced CBC seemed to be strongest in women who developed their second primary breast tumour at least 5 years after radiotherapy. Those patients had an odds ratio of 2.51 (95\% confidence interval 1.03 to $6.10 ; p=0.049$ ) of developing radiation-induced breast cancer, in comparison with non-carriers.

Conclusion This study shows that carriers of germline mutations in a DDRP gene have an increased risk of developing (contralateral) breast cancer after radiotherapy; that is, over and above the risk associated with their carrier status. The increased risk indicates that knowledge of germline status of these DDRP genes at the time of breast cancer diagnosis may have important implications for the choice of treatment.

\section{Introduction}

Several risk factors for the development of breast cancer, such as family history, reproductive factors and exposure to radiation, have been identified. Out of all breast cancers, 5 to $10 \%$ can be attributed to germline mutations in familial high-risk genes such as $B R C A 1$ or $B R C A 2$ that result in a lifetime breast cancer risk of about 45 to $65 \%$ [1]. The penetrance varies between families, depending on 'risk modifiers' such as hormonal factors, mutation type and also exposure to radiation
[2-4]. Mutations in low-penetrance genes may account for a larger proportion (10 to 30\%) of all breast cancers [5]. The contribution of these genes might be explained by their role in the DNA-damage control pathway. For instance, ATM heterozygous carriers have a relative risk of breast cancer of 2.2 compared with the general population and a relative risk of 4.9 for those younger than 50 years of age $[6,7]$. It has been shown that particular alterations in the ATM gene are associated with increased in vitro chromosomal sensitivity to

$\overline{\mathrm{CBC}}=$ contralateral breast cancer; $\mathrm{Cl}=$ confidence interval; $\mathrm{DDRP}=\mathrm{DNA}$-damage repair pathway; $\mathrm{OR}=$ odds ratio; $\mathrm{RT}=$ radiation treatment. 
radiation [8-10]. One particular sequence variant in CHEK2 (CHEK2*1100de/C) has been implicated in a twofold increased risk of breast cancer, functioning as a low-penetrance breast cancer susceptibility allele [11-15]. Mutation frequencies reported in the literature indicate that about $10 \%$ of all women with breast cancer diagnosed before the age of 50 years have a germline mutation in BRCA1, BRCA2, ATM or CHEK2 [1,6,15].

Exposure to ionising radiation is a strong risk factor for breast cancer. A pooled analysis of eight cohorts by Preston and colleagues showed that the increased risk is directly proportional to the radiation dose received and inversely related to age at irradiation [16]. For women exposed at the age of 25 years the excess relative risk per Gy was estimated to be 1.8. Radiationinduced DNA damage initiates a complex series of overlapping responses responsible for the maintenance of genome integrity. The increased incidence of breast cancer after exposure to ionising radiation might be restricted to a genetically defined radiosensitive subpopulation [17]. Candidate genes (for example BRCA1, BRCA2, CHEK2, ATM, MDM2 and TP53) are implicated in the maintenance of genome integrity; their involvement in breast cancer susceptibility and their role in DNA-damage repair signalling make them excellent candidates as genes with a role in radiation-induced breast cancer [18].

The use of diagnostic X-rays has not been associated with increased risk of breast cancer in the general population, with the exception of frequent chest fluoroscopies in tuberculosis $[19,20]$. However, low-dose ionising radiation has recently been shown to increase the risk of breast cancer significantly among $B R C A 1$ and $B R C A 2$ mutation carriers [4]. In a retrospective cohort study of 1,601 female BRCA1 and BRCA2 mutation carriers we found an association with reported chest $\mathrm{X}$-ray exposure and significantly increased risk of breast cancer (hazard ratio 1.54). Furthermore, a recent publication also showed a strong association (odds ratio (OR) 3.21) between CHEK2 ${ }^{*} 1100$ de/C carrier status, breast cancer risk and a history of chest X-rays [21].

Women with breast cancer in general have a threefold to fourfold increased risk of developing a new primary cancer in the opposite breast [22]. The increased risk may be explained by the same genetic and hormonal factors that caused the first breast cancer. In addition, radiotherapy for primary breast cancer may also contribute to the development of cancer in the contralateral breast. The contralateral breast can receive a dose of several Gy of leakage and scattered radiation during radiation treatment $(R T)[23,24]$. Several studies have shown that exposure of the contralateral breast to RT increases the risk of developing second primary breast cancer among young women $[23,25]$.
To evaluate the association between germline mutations in DNA-damage repair pathway (DDRP) genes (BRCA1, $B R C A 2, C H E K 2$ and $A T M$ ) and radiation-induced contralateral breast cancer (CBC), we conducted a case-only study. We assessed the germline mutation frequency in women who developed CBC, according to their history of RT for the first breast cancer, and assessed whether DDRP mutation carriers have an increased risk of radiation-associated breast cancer compared with that for non-carriers.

\section{Methods \\ Patients}

We examined the interaction of germline mutation status and exposure to radiotherapy in the pathogenesis of CBC in a case-only design. Such an approach is especially suitable for the evaluation of gene-environment interactions $[26,27]$. The consecutive breast cancer patients included in this study were all selected from the hospital tumour registries of The Netherlands Cancer Institute (NKI-AVL), Amsterdam, and the Dr Daniel den Hoed Cancer Centre/Erasmus Medical Center (DDHK), Rotterdam. We achieved an $80 \%$ response rate from all patients who were invited to participate. CBC patients (with a histologically confirmed second primary breast tumour) were included if their first breast cancer was diagnosed before the age of 50 years (between 1966 and 2000) and the second breast cancer was diagnosed at least 1 year later $(n=247)$.

One hundred and sixty-nine patients had received radiotherapy for their primary invasive breast tumour and 78 had not (main indications for radiotherapy were lymph-node status and prognosis at the time of diagnosis). All patients had been treated with surgery, $23 \%$ had had chemotherapy in addition to $\mathrm{RT}$, and $9 \%$ had received chemotherapy in the no-RT group (see also Table 1). Patients who were treated with radiotherapy received one or more radiation fields with either kilovolt or megavolt radiation quality. The dose to the ipsilateral primary tumour site varied from 30.5 Gy (internal mammary chain irradiation) to 76 Gy (breast-conserving treatment with a boost dose). The contralateral breast received about 1 to $10 \%$ from scatter and collimator leakage (this problem continues despite modern radiation methods). The maximum radiation dose at the contralateral breast and the dose at the site of the contralateral tumour were estimated from the treatment charts by a radiation oncologist (NS Russell; details of the calculation of the radiation dose to the contralateral breast (taking into account all given doses, fields, machine types, scatter and collimator leakage) are available from the authors on request).

Detailed treatment data, disease characteristics and patient characteristics were obtained from medical records and risk factor questionnaires (Table 1). Patients were asked to donate a 20-ml blood sample or permission for the use of paraffinembedded tissue blocks, and all patients gave written informed consent for mutation analysis. This study received 
Table 1

\begin{tabular}{|c|c|c|c|c|}
\hline \multirow[t]{2}{*}{ Characteristic } & \multicolumn{2}{|c|}{ Mutation positive $(n=51)$} & \multicolumn{2}{|c|}{ Mutation negative $(n=196)$} \\
\hline & Previous RT & No previous RT & Previous RT & No previous RT \\
\hline Age at first $B C$, years & 40.3 & 42.4 & 41.4 & 42.3 \\
\hline Age at second $\mathrm{BC}$, years & 48.1 & 51.8 & 51.1 & 54.2 \\
\hline Chemotherapy, $n$ (percentage) & $11(27)$ & $1(10)$ & $28(22)$ & $5(7)$ \\
\hline Tumour size, $\mathrm{cm}$ & 1.8 & 2.9 & 2.2 & 2.3 \\
\hline Lymph node positive, $n$ (percentage) & $12(29)$ & $1(10)$ & $41(32)$ & $4(6)$ \\
\hline \multicolumn{5}{|l|}{ RT dosea, Gy } \\
\hline Mean (range) & $1.49(0.27-3.73)$ & & $1.55(0.24-5.61)$ & \\
\hline Median & 1.32 & & 1.40 & \\
\hline Third quartile & 1.79 & & 1.89 & \\
\hline
\end{tabular}

DDRP, DNA-damage repair pathway; BC, breast cancer; RT, radiation treatment. aRadiation dose to the site of the breast where the tumour had developed.

approval from the Medical Ethical Committees of NKI-AVL and DDHK.

\section{Genomic DNA isolation}

Genomic DNA was either isolated from peripheral blood lymphocytes with the use of DNAzol (Invitrogen, Breda, The Netherlands) methods in accordance with the manufacturer's instructions, or from three 10- $\mu \mathrm{m}$ paraffin normal tissue slides in accordance with standard protocols [28]. For histopathological examination of the tumour we used a haematoxylin/ eosin-stained slide.

\section{Mutation analysis}

The complete ATM open reading frame was analysed; each exon (exons 4 to 65 ) and corresponding splice sites were screened for germline mutations by denaturing gradient gel electrophoresis, identifying 80 to $90 \%$ of all ATM mutations and polymorphisms [29]. Detection of the CHEK2*1100de/C mutation was performed by using denaturing gradient gel electrophoresis. All primers were designed with the Ingeny melt analysis software; and primer sequences are available from the authors on request. The products were analysed on a polyacrylamide/20 to $55 \%$ urea/formamide gradient gel and run overnight at $120 \mathrm{~V}$ and $59^{\circ} \mathrm{C}$.

Using DSDI (detection of small deletions and insertions; genotype analysis on an ABI Prism 3700 DNA analyzer and corresponding software) and allelic discrimination (AD; with Taqman probes using a $\mathrm{ABI}$ Prism 7700 sequence detector) we screened for BRCA1 and BRCA2 mutations. We chose the fragments for DSDI and the ADs as those in which we were able to detect the most frequently occurring known pathogenic mutations, including Dutch founder mutations, on the basis of data from BRCA1/2 screening in breast cancer fami- lies and in young breast cancer patients from almost all clinical genetic centres in The Netherlands. In total we screened for 32 different mutations in BRCA1 and 16 in BRCA2, which represented at the time of analysis about $81 \%$ and about $39 \%$ of known mutations occurring in Dutch breast cancer families. Methods are available from the authors on request.

All aberrations were confirmed by genomic sequence analysis. Sequence analysis was performed with the ABI PRISM BigDyeTerminator Cycle Sequencing Ready Reaction Kit, Version 3.1 (Applied Biosystems, Nieuwerkerk a/d ljssel, The Netherlands). Sequencing products were analysed with the $A B I$ Prism 3700 DNA analyser and corresponding software.

\section{Statistical analysis}

Statistical analyses were performed by using standard methods for the analysis of case-control studies [30]. We compared the mutation frequency between $\mathrm{CBC}$ cases previously treated with radiation and those not treated with radiation. ORs and $95 \%$ confidence intervals ( $\mathrm{Cls}$ ) were calculated to evaluate the association between radiation exposure, mutation carrier status and breast cancer risk. Logistic regression was performed to examine the effect of potential confounders (age at first breast cancer, tumour size, lymph node status and family history) on risk estimates. Under the assumption that there is independence between genotype and RT, the OR estimates the relative risk of $\mathrm{CBC}$ associated with radiation among gene carriers compared with the relative risk of $\mathrm{CBC}$ associated with radiation among non-carriers. All analyses were performed with SPSS 12.0 (SPSS Inc., Chicago, IL, USA). 
Table 2

Frequencies of contralateral breast cancer patients $\mathrm{CBC}$ carrying apathogenic DNA-damage repair pathway mutation

\begin{tabular}{|c|c|c|c|c|c|c|c|c|c|c|}
\hline \multirow[t]{2}{*}{ Parameter } & \multirow[t]{2}{*}{$\begin{array}{l}\text { Breast cancer }<50 \text { years }{ }^{a} \\
\text { (percentage) }\end{array}$} & \multicolumn{2}{|c|}{$\begin{array}{l}\text { All CBC patients } \\
(n=247)\end{array}$} & \multicolumn{2}{|c|}{ Previous RT $(n=169)$} & \multicolumn{2}{|c|}{ No RT $(n=78)$} & \multicolumn{3}{|c|}{ Carriers versus non-carriers } \\
\hline & & $n$ & Percentage & $n$ & Percentage & $n$ & Percentage & OR for CBC after RT & $95 \% \mathrm{Cl}$ & $p$ \\
\hline DDRP mutated & $\sim 10$ & 51 & 21 & 41 & 24.3 & 10 & 12.8 & 2.18 & $1.03-4.62$ & 0.043 \\
\hline CHEK2 & $1-2$ & 15 & 6.1 & 13 & 7.7 & 2 & 2.6 & 3.17 & $0.69-14.39$ & \\
\hline$B R C A 1$ & $\sim 4-5$ & 27 & 11.3 & 20 & 11.8 & 7 & 9 & 1.36 & $0.55-3.37$ & \\
\hline$B R C A 2$ & $\sim 0.5-1$ & 5 & 2 & 4 & 2.4 & 1 & 1.3 & 1.87 & $0.21-16.98$ & \\
\hline \multirow[t]{2}{*}{ ATM truncating } & $\sim 1-2$ & 4 & 1.6 & 4 & 2.4 & 0 & 0 & - & - & \\
\hline & & & & & & $1^{\mathrm{b}}$ & 1.3 & 1.87 & $0.21-16.98$ & \\
\hline
\end{tabular}

Results for all contralateral breast cancer (CBC) patients, and patients stratified by previous radiation exposure, are presented. Odds ratio (OR) and $95 \%$ confidence interval $(\mathrm{Cl})$ are given for mutation carriers versus non-carriers to develop radiation-associated breast cancer. DDRP, DNAdamage repair pathway; RT, radiation treatment. aPublished results; bHypothetical assumption of one case.

\section{Results \\ Pathogenic and missense mutation frequencies}

For all $\mathrm{CBC}$ patients we obtained germline mutation data for the DDRP genes BRCA1, BRCA2, CHEK2 and ATM. In total, we identified 51 pathogenic germline mutations in these DDRP genes among the 247 CBC patients (21\%), an increase over the estimated $10 \%$ mutation carriers among all women with primary breast cancer diagnosed before the age of 50 years (estimated from mutation frequencies reported previously $[1,6,15]$; Table 2). We did not detect multiple pathogenic mutations in single patients. We compared the mutation frequency between CBC cases previously treated with radiation and those not treated with radiation. Among women who had received radiotherapy for their first breast cancer ( $n$ $=169$ ), we identified $24.3 \%$ mutation carriers, in contrast with only $12.8 \%$ among those who had not received radiotherapy $(n=78)$. Our data show that women with a pathogenic mutation in one of the tested genes have a 2.18-fold increased risk (95\% Cl 1.03 to 4.62 ) of developing CBC after radiotherapy for the first breast cancer, compared with women without a pathogenic mutation. The pattern of a higher proportion of carriers among the $\mathrm{CBC}$ cases with previous RT than among those with no previous RT was also found for each of the individual genes, although these results did not reach significance.

The mean age at diagnosis of the first primary breast cancer was 41 years in the CBC group with previous RT and 42 years for $\mathrm{CBC}$ patients not treated with radiation (Table 1). Furthermore, the mean age at diagnosis of the first primary breast cancer was 41 years in the mutation carrier group (interquartile range 36 to 47 years) and 42 years in the non-carriers (interquartile range 38 to 47 years), resulting in the same mean (and median) age at time of treatment in both groups. Adjustment for age in logistic regression analysis did not materially affect the risk estimates: the adjusted OR was $2.14(95 \% \mathrm{Cl}$ 1.01 to 4.55$)$. DDRP mutation carriers had clinico-pathological features that were similar to those of 'sporadic' cases. Tumour size, lymph node status and type of tumour were comparable in the mutation-positive and mutation-negative groups (Table 1). Adjustment for each of these three factors in logistic regression analysis did not materially affect the risk estimates for mutation status.

Table 3

Frequencies of CBC patients carrying pathogenic DNA-damage repair pathway and ATM missense mutations

\begin{tabular}{|c|c|c|c|c|c|c|c|c|c|}
\hline \multirow[t]{2}{*}{ Parameter } & \multicolumn{2}{|c|}{$\begin{array}{l}\text { All CBC patients } \\
(n=247)\end{array}$} & \multicolumn{2}{|c|}{$\begin{array}{l}\text { Previous RT } \\
(n=169)\end{array}$} & \multicolumn{2}{|c|}{$\begin{array}{l}\text { No RT } \\
(n=78)\end{array}$} & \multicolumn{3}{|c|}{ Carriers versus non-carriers } \\
\hline & $n$ & Percentage & $n$ & Percentage & $n$ & Percentage & OR for CBC after RT & $95 \% \mathrm{Cl}$ & $p$ \\
\hline DDRP mutated & 51 & 21 & 41 & 24.3 & 10 & 12.8 & 2.18 & $1.03-4.62$ & 0.043 \\
\hline All patients with only a pathogenic DDRP mutation & 37 & 15 & 29 & 17.2 & 8 & 10.3 & 1.8 & $0.79-4.17$ & \\
\hline $\begin{array}{l}\text { Patients with both a pathogenic DDRP and an ATM } \\
\text { missense mutation }\end{array}$ & 14 & 5.7 & 12 & 7.1 & 2 & 2.6 & 2.90 & $0.63-13.30$ & \\
\hline Patients with only an $A T M$ missense mutation & 29 & 11.7 & 21 & 12.4 & 8 & 10.3 & 1.24 & $0.52-2.94$ & \\
\hline
\end{tabular}

Results for all contralateral breast cancer (CBC) patients, and patients stratified by previous radiation exposure, are presented. Odds ratio (OR) and $95 \%$ confidence interval $(\mathrm{Cl})$ are given for mutation carriers versus non-carriers to develop radiation-associated breast cancer. DDRP, DNAdamage repair pathway; $\mathrm{RT}$, radiation treatment. 
Table 4

Frequencies of $\mathrm{CBC}$ patients carrying apathogenic DNA-damage repair pathway mutation

\begin{tabular}{|c|c|c|c|c|c|c|c|c|}
\hline \multirow[t]{2}{*}{ Age (years) } & \multicolumn{2}{|c|}{ All CBC patients } & \multicolumn{2}{|c|}{ Previous RT } & \multicolumn{2}{|c|}{ No RT } & \multicolumn{2}{|c|}{ Carriers versus non-carriers } \\
\hline & $n$ & Percentage & $n$ & Percentage & $n$ & Percentage & OR for CBC after RT & $95 \% \mathrm{Cl}$ \\
\hline$<40(n=91)$ & $22 / 91$ & 24 & $19 / 67$ & 28 & $3 / 24$ & 12 & 2.77 & $0.74-10.39$ \\
\hline $40-50(n=156)$ & $29 / 156$ & 18.6 & $22 / 102$ & 21.6 & $7 / 54$ & 12.9 & 1.85 & $0.73-4.65$ \\
\hline
\end{tabular}

Results for all contralateral breast cancer (CBC) patients, and patients stratified by previous radiation exposure, are presented, according to age at diagnosis of first primary breast cancer (before the age of 40 years or between 40 and 50 years of age). Odds ratio (OR) and $95 \%$ confidence interval $(\mathrm{Cl})$ are given for mutation carriers versus non-carriers to develop radiation-associated breast cancer. RT, radiation treatment.

In addition to the proven ATM pathogenic truncating mutations we also detected in $A T M$ a large number of presumed neutral polymorphisms and missense mutations (Table 3). Forty-three individuals carried at least one ATM missense mutation, of whom 7 had multiple ATM missense mutations [31]. Moreover, 14 patients had a pathogenic mutation in one of the tested DDRP genes in addition to an ATM missense mutation. Overall, we did not detect a significantly increased proportion of women with missense mutations among those who had received RT compared with those who had not (OR $1.24(95 \% \mathrm{Cl} 0.52$ to 2.94$))$. Although these data are also not statistically significant, there might be an increased risk of developing radiation-induced breast cancer in those women carrying a combination of both a pathogenic DDRP and an ATM missense mutation (OR 2.90 (95\% Cl 0.63 to 13.30); Table 3).

The literature $[6,41]$ shows that $A T M$ missense mutation carriers have an increased risk for breast cancer. Because there is no conclusive evidence for the function of any of these missense mutations yet, we did not take these missense mutations into account in the subsequent analysis exploring the effect of RT.

\section{Effects of age at radiation, radiation dose, and induction period}

Because age at radiation is a major determinant of breast cancer risk, we examined whether younger age at irradiation was associated with a greater radiation effect in carriers. All women in our study had their first breast tumour diagnosed before the age of 50 years, but none of them had cancer before they were 20 years old. We divided the cases by age at radiation into those exposed below the age of 40 years and those exposed between 40 and 50 years of age. Although the results were not significant, they showed that the radiation effect might be more pronounced in the younger mutation carriers at exposure (Table 4).

The contralateral breast received about 1 to $10 \%$ of the total dose from scatter and collimator leakage from the RT machine. To investigate whether germline pathological mutations most strongly affect CBC risk in women who had highest levels of RT (women were received a dose of 30 to 76 Gy), we compared the estimated maximum radiation dose to the contralateral breast with the estimated radiation dose at the site of the tumour in the contralateral breast between mutation carriers and non-carriers. The mean maximum RT dose and dose at the site of the tumour in the (contralateral) breast were comparable for those patients carrying a germline mutation and those without a germline mutation (Table 1). The dose distribution among carriers and non-carriers was also comparable, with an interquartile range for maximum RT dose of 1.0 to 1.8 Gy among carriers and 0.9 to 1.9 Gy among non-carriers, and an interquartile range for the dose at the site of the tumour of 1.3 to 2.2 Gy among carriers and 1.5 to 2.8 Gy among noncarriers.

The literature suggests that the increased risk of breast cancer due to radiation is not observed until at least 5 years after exposure [32,33]. When we subdivided all cases into two

Table 5

Frequencies of CBC patients carrying apathogenic DNA-damage repair pathway mutation

\begin{tabular}{|c|c|c|c|c|c|c|c|c|c|}
\hline \multirow[t]{2}{*}{ Interval (years) } & \multicolumn{2}{|c|}{ All CBC patients } & \multicolumn{2}{|c|}{ Previous RT } & \multicolumn{2}{|c|}{ No RT } & \multicolumn{3}{|c|}{ Carriers versus non-carriers } \\
\hline & $n$ & Percentage & $n$ & Percentage & $n$ & Percentage & OR for CBC after RT & $95 \% \mathrm{Cl}$ & $p$ \\
\hline $1-5(n=66)$ & $15 / 66$ & 22.7 & $12 / 49$ & 24.5 & $3 / 16$ & 18.8 & 1.41 & $0.34-5.78$ & \\
\hline$>5(n=181)$ & $36 / 181$ & 19.9 & $29 / 120$ & 24.1 & $7 / 62$ & 11.3 & 2.51 & $1.03-6.10$ & 0.049 \\
\hline
\end{tabular}

All contralateral breast cancer (CBC) patients, and patients stratified by previous radiation exposure are presented, according to interval between first and second primary breast cancer (less than 5 and more than 5 years). Odds ratio (OR) and $95 \%$ confidence interval (Cl) are given for mutation carriers versus non-carriers to develop radiation-associated breast cancer. RT, radiation treatment. 
groups on the basis of the interval between first and second breast cancer ( 1 to 5 years and more than 5 years), we did indeed observe a difference between these groups (Table 5). The strongest effect was observed in women who developed a second primary breast tumour at least 5 years after radiotherapy; of these, $24 \%$ carried a germline mutation in one of the genes tested, in contrast with only $11 \%$ in those who did not receive any RT. Thus, at least 5 years after RT for the first breast cancer, women carrying a germline mutation in a DDRP gene had a significantly increased risk (OR 2.51, 95\% Cl 1.03 to $6.10 ; p=0.049$ ) of developing a radiation-associated CBC compared with women not carrying such a mutation.

\section{Discussion}

This study is, to the best of our knowledge, the first to suggest that women with a germline mutation in a gene involved in DDRP have an increased risk of developing radiation-associated $\mathrm{CBC}$, compared with women who are not carrying such a mutation. We examined the mutation frequency of $B R C A 1$, BRCA2, CHEK2 and ATM in women who had developed a second primary breast tumour at least 1 year after a first breast cancer diagnosed before the age of 50 years, with or without RT for their first breast cancer. Such a case-only design is particularly well suited to the assessment of gene-environment interactions, although the independent effects of the genes involved or of radiation cannot be determined from these data $[26,27]$. ORs from such a design can be interpreted as the risk of developing radiation-associated disease for carriers compared with non-carriers. We present evidence for an interaction between mutations in the DDRP genes and radiation for the first breast cancer in the development of CBC.

Women with breast cancer have in general a threefold to fourfold increased risk of developing a new primary cancer in the contralateral breast [22]. The 15-year cumulative risk of developing CBC amounts to 10 to 13\% [34-36]. BRCA1 and $B R C A 2$ mutation carriers have an estimated $C B C$ cumulative risk of 50 to $60 \%$ at the age of 70 years. The highest incidence is seen in the first 5 years after diagnosis of the primary breast cancer (12 to 33\% per year), in contrast with 0.4 to $1 \%$ per year for breast cancer patients in general $[37,38]$. In a recent study, based on a consecutive series of breast cancer patients under 50 years of age, unselected for family history, we showed that CHEK2*1100de/C carriers have a twofold increased risk of second breast cancer [39].

In the present study we found that mutation carriers have an additional excess risk, compared with non-carriers, of developing CBC during follow-up if they received RT for their first breast tumour. The increased risk due to RT exposure in carriers was mainly seen from 5 years after RT (Table 5). This is in accordance with the analysis of Boice and colleagues, who suggested previously that cancers resulting from an exposure to radiation would develop within predictable time windows; a latency period of at least 5 to 10 years was suggested for sec- ond primaries [32]. Metcalf and colleagues have shown that RT actually protects against local recurrences and ipsilateral breast cancer among BRCA1 and BRCA2 carriers [36].

Age at time of exposure is known to be a major determinant of the risk of breast cancer [40]. Our data also suggest that carriers in the younger age group at the time of exposure (less than 40 years old) showed the highest risk of developing radiation-associated $\mathrm{CBC}$, although the difference from those above 40 years of age at RT was not significant (Table 4). Importantly, the mean and median ages at diagnosis of the first primary breast cancer were the same in the CBC patients with and without prior RT and in CBC patients with and without a germline mutation, resulting in the same median age at time of treatment in both groups (Table 1). Indeed, adjustment for age at first diagnosis did not affect our risk estimates.

The association between breast cancer risk and low-dose radiation has been a subject of debate. Recently we showed that diagnostic ionising radiation exposure from chest $\mathrm{X}$-rays may be associated with a significantly increased breast cancer risk among women who carry $B R C A 1$ or $B R C A 2$ pathogenic germline mutations [4]. Comparable findings were reported for CHEK2 ${ }^{*} 1100$ de/C carriers by Bernstein and colleagues [21]. In the present study we included women exposed to higher doses from therapeutic RT, in whom the contralateral breast is exposed to about 1 to $10 \%$ of the total dose (namely 1 to $6 \mathrm{~Gy}$ ), increasing the likelihood of detecting a gene-radiation interaction. The average (mean and median) maximum radiation dose (about $1.5 \mathrm{~Gy}$ ) and the dose at the site of the tumour (about $1.8 \mathrm{~Gy}$ ) measured in this study were found to be comparable between carriers and non-carriers. According to Preston and colleagues, the excess relative risk at $1 \mathrm{~Gy}$ is 2 , implying that mutation carriers may have an excess relative risk of about 2.5 times this risk [16].

We increased the power of our analysis by investigating the effect of four breast cancer susceptibility genes together, considering them as a DNA repair gene group. These genes are all involved in DNA damage response triggered by damage induced by ionising radiation. An efficient response to DNA damage is essential for cellular life. The most detrimental form of damage is DNA double-strand breaks, which can be induced by ionising radiation and are lethal to the cell if not repaired. If repaired incorrectly, as a result of improper functioning of the repair machinery caused by mutations in the genes implicated, double-strand breaks can lead to carcinogenesis through translocation, inversions or deletions of genetic material. Although the relative impact of germline mutations in the separate genes studied in response to RT is unknown, all of these genes have been identified as crucial to the repair of RT-induced double-strand breaks. We therefore considered it justified to regard these genes together as a DNA repair gene group in our analyses. Although we screened for only a subset of all mutations in the four genes, there is no 
biological evidence that undetected mutations would have occurred more often in the non-RT group.

In a case-only study there must be independence between exposure (RT) and genotype (mutation) [26]. By selecting the RT-exposed and non-RT-exposed groups of CBC patients we might have consistently selected for those clinico-pathological factors determining the use of radiotherapy. If mutation carriers were more likely to receive RT for primary breast cancer, for example because of the presence of a family history of the disease, alerting the physician to a potentially more aggressive course of the disease, selection bias might arise in our caseonly study. However, this was not the case, mutation carriers did not receive RT more often. Information about a family history of breast cancer was obtained by a mailed questionnaire and from medical records. In our study population 53\% of the carriers reported breast cancer in the family (33\% with an affected first-degree relative), in contrast with $40 \%$ in the noncarriers (29\% with an affected first-degree relative). From the data collected from medical records and risk factor questionnaires of all women, we concluded that DDRP mutation carriers had clinico-pathological features (such as size and stage) similar to those of 'sporadic' cases. Adjustment for each of these factors in logistic regression analysis did not materially affect the risk estimates for mutation status. In addition, the percentages of patients receiving chemotherapy were comparable for mutation carriers and non-carriers. Consequently, the genetic factors (the genetic status was not known at time of treatment) under study did not affect treatment choice, justifying our assumption of independence between radiation and a mutation carrier status, which is needed for a case-only study.

In addition, in a related project studying the effect of $B R C A 1$, $B R C A 2$ and $C H E K 2 * 1100 d e / C$ germline mutations on survival and disease outcome in a large cohort of unselected breast cancer patients (diagnosis before 50 years of age), we found that the tumour characteristics of CHEK2*1100de/C carriers did not differ significantly from those of non-carriers. Importantly, in that same study we also found that the proportion of breast cancer patients receiving radiotherapy did not significantly differ between the CHEK2*1100de/C carriers and non-carriers [39].

Although the effect of pathogenic DDRP gene mutations on breast cancer risk seems evident, the role of most ATM missense mutations remains unclear. Generally, the idea is that there are two groups of ATM heterozygotes in the general population, each with different cancer risks: those with a wildtype and a truncating mutation allele and those with a wild-type and a missense mutation allele. Several epidemiological studies have shown that relatives of patients with ataxia-telangiectasia heterozygotic for an ATM germline mutation have an increased risk of breast cancer [6]. Carriers of mutations predicted to encode a full-length ATM protein had cancer risks similar to those of people carrying truncating mutations, predicting that both type of mutation in these families are pathogenic for ataxia-telangiectasia as well as for breast cancer $[6,41]$. Most studies try to predict the relevance of a particular mutation on the basis of co-segregation in breast cancer families, the location in a functional domain or interference with the splicing machinery [42]. Nevertheless, only a few studies have presented the functional analyses necessary to assess the biological impact of unidentified variants found frequently in ATM [43]. We found that $A T M$ missense mutations, those detected in our study, do not by themselves contribute to an increased risk of breast cancer after exposure to radiation. Although not significant, there might be an increased risk of developing CBC after RT when patients have both a pathogenic DDRP and an ATM missense mutation (Table 3 ). This trend suggests that $A T M$ missense mutations might have a risk-modifying effect after radiation exposure.

It has been hypothesised that a multigenic model might explain breast cancer susceptibility in a large part of the population. It has been shown that, although mutations in certain genes had marginal or no associations with risk when studied in isolation, they showed significant association when combined with variant alleles in other genes [44]. It will be necessary to confirm the potential pathogenic-missense mutation (gene-gene) interaction findings of this study by a larger-scale study designed specifically to examine the joint effects of radiation exposure and genetic susceptibility of breast cancer risk (for example the Women's Environmental Cancer and radiation epidemiology ('WECARE') study [45]).

\section{Conclusion}

Our data imply that there is a subgroup in the female population with increased susceptibility to radiation-induced breast cancer. The characterisation and identification of such a radiosensitive subgroup, if confirmed by others, will have implications for both diagnostic testing and the need for tailored treatment strategies. It provides a scientific basis for mutation analysis and subsequently, following the mutation analysis, an intensified follow-up protocol for mutation carriers. Identification of women susceptible to radiation damage will contribute to the risk/benefit assessment of radiation therapy versus alternative therapeutic options (such as breast-conserving surgery plus local radiotherapy or mastectomy).

\section{Competing interests}

The authors declare that they have no competing interests.

\section{Authors' contributions}

$A B$ was involved in coordination of the study, performing the experiments and analysing results, and wrote the manuscript. $\mathrm{LMB}, \mathrm{AH}$ and $\mathrm{JU}$ were involved in the mutation analysis experiments. AN was involved in patient selection, medical record and questionnaire abstraction and database management. $\mathrm{FH}$ participated in mutation identification management. MKS participated in the SPSS statistical and database analysis. JGMK 
participated in patient identification and selection. NSR participated in patient selection and provided radiation dosimetry. FEvL participated in the design and epidemiological analysis and LJV participated in the design and coordination of the study. All authors read and approved the final manuscript.

\section{Acknowledgements}

We thank Harry Bartelink for critical comments and advice on the manuscript, and Arno Floore, Arnout van der Plas, Astrid Bosma and Ben Nota for helping with the mutation analysis. Funding of this study was provided by the Dutch Cancer Society (DCS-NKI 01-2425).

\section{References}

1. Antoniou A, Pharoah PD, Narod S, Risch HA, Eyfjord JE, Hopper $\mathrm{JL}$, Loman $\mathrm{N}$, Olsson $\mathrm{H}$, Johannsson $\mathrm{O}$, Borg $\mathrm{A}$, et al:: Average risks of breast and ovarian cancer associated with BRCA1 or BRCA2 mutations detected in case series unselected for family history: a combined analysis of $\mathbf{2 2}$ studies. Am J Hum Genet 2003, 72:1117-1130.

2. Narod SA: Modifiers of risk of hereditary breast and ovarian cancer. Nat Rev Cancer 2002, 2:113-123.

3. Narod SA, Foulkes WD: BRCA1 and BRCA2: 1994 and beyond. Nat Rev Cancer 2004, 4:665-676.

4. Andrieu N, Easton DF, Chang-Claude J, Rookus MA, Brohet R, Cardis E, Antoniou AC, Wagner T, Simard J, Evans G, et al:: Effect of chest X-rays on the risk of breast cancer among BRCA1/2 mutation carriers in the international BRCA1/2 carrier cohort study: a report from the EMBRACE, GENEPSO, GEO-HEBON, and IBCCS Collaborators' Group. I Clin Oncol 2006, 24:3361-3366

5. Dumitrescu RG, Cotarla I: Understanding breast cancer risk where do we stand in 2005? J Cell Mol Med 2005, 9:208-221.

6. Thompson D, Duedal S, Kirner J, McGuffog L, Last J, Reiman A, Byrd P, Taylor M, Easton DF: Cancer risks and mortality in heterozygous ATM mutation carriers. J Natl Cancer Inst 2005, 97:813-822.

7. Broeks A, Urbanus JH, Floore AN, Dahler EC, Klijn JG, Rutgers EJ, Devilee P, Russell NS, van Leeuwen FE, van't Veer LJ: ATM-heterozygous germline mutations contribute to breast cancersusceptibility. Am J Hum Genet 2000, 66:494-500.

8. Gutierrez-Enriquez $S$, Fernet $M$, Dork T, Bremer M, Lauge $A$, Stoppa-Lyonnet D, Moullan N, Angele S, Hall J: Functional consequences of ATM sequence variants for chromosomal radiosensitivity. Genes Chromosomes Cancer 2004, 40:109-119.

9. Smilenov LB, Brenner DJ, Hall EJ: Modest increased sensitivity to radiation oncogenesis in ATM heterozygous versus wildtype mammalian cells. Cancer Res 2001, 61:5710-5713.

10. Angele $S$, Romestaing $P$, Moullan $N$, Vuillaume $M$, Chapot $B$, Friesen M, Jongmans W, Cox DG, Pisani P, Gerard JP, Hall J: ATM haplotypes and cellular response to DNA damage: association with breast cancer risk and clinical radiosensitivity. Cancer Res 2003, 63:8717-8725.

11. Vahteristo $P$, Bartkova J, Eerola $H$, Syrjakoski K, Ojala S, Kilpivaara O, Tamminen A, Kononen J, Aittomaki K, Heikkila P, et al.: A CHEK2 genetic variant contributing to a substantial fraction of familial breast cancer. Am J Hum Genet 2002, 71:432-438.

12. Offit $K$, Pierce $H$, Kirchhoff $T$, Kolachana $P$, Rapaport $B$, Gregersen $\mathrm{P}$, Johnson S, Yossepowitch O, Huang H, Satagopan J, et al.: Frequency of CHEK2*1100delC in New York breast cancer cases and controls. BMC Med Genet 2003, 4:1.

13. Sodha N, Bullock S, Taylor R, Mitchell G, Guertl-Lackner B, Williams RD, Bevan S, Bishop K, McGuire S, Houlston RS, Eeles RA: CHEK2 variants in susceptibility to breast cancer and evidence of retention of the wild type allele in tumours. $\mathrm{Br} J$ Cancer 2002, 87:1445-1448.

14. Meijers-Heijboer $\mathrm{H}$, van den Ouweland A, Klijn J, Wasielewski M, de Snoo A, Oldenburg R, Hollestelle A, Houben M, Crepin E, van Veghel-Plandsoen $M$, et al.: Low-penetrance susceptibility to breast cancer due to CHEK2*1100delC in noncarriers of BRCA1 or BRCA2 mutations. Nat Genet 2002, 31:55-59.
15. CHEK2 Breast Cancer Case-Control Consortium: CHEK2*1100delC and susceptibility to breast cancer: a collaborative analysis involving 10,860 breast cancer cases and 9,065 controls from 10 studies. Am J Hum Genet 2004 74:1175-1182.

16. Preston DL, Mattsson A, Holmberg E, Shore R, Hildreth NG, Boice JD Jr: Radiation effects on breast cancer risk: a pooled analysis of eight cohorts. Radiat Res 2002, 158:220-235.

17. Scott D: Chromosomal radiosensitivity and low penetrance predisposition to cancer. Cytogenet Genome Res 2004, 104:365-370.

18. Bennett LM: Breast cancer: genetic predisposition an exposure to radiation. Mol Carcinog 1999, 26:143-149.

19. Boice JD Jr, Monson RR: Breast cancer in women after repeated fluoroscopic examinations of the chest. J Nat/ Cancer Inst 1977, 59:823-832

20. Morin Doody M, Lonstein JE, Stovall M, Hacker DG, Luckyanov N, Land CE: Breast cancer mortality after diagnostic radiography: findings from the U.S. Scoliosis Cohort Study. Spine 2000, 25:2052-2063.

21. Bernstein JL, Teraoka SN, John EM, Andrulis IL, Knight JA, Lapinski $\mathrm{R}$, Olson ER, Wolitzer AL, Seminara D, Whittemore AS, Concannon P: The CHEK2*1100delC allelic variant and risk of breast cancer: screening results from the Breast Cancer Family Registry. Cancer Epidemiol Biomarkers Prev 2006, 15:348-352.

22. Harvey EB, Brinton LA: Second cancer following cancer of the breast in Conneticut, 1935-1982. Natl Cancer Inst Monogr 1985, 68:99-112.

23. Boice JD Jr, Harvey EB, Blettner M, Stovall M, Flannery JT: Cancer in the contralateral breast after radiotherapy for breast cancer. N Engl J Med 1992, 326:781-785.

24. Roychoudhuri R, Evans $\mathrm{H}$, Robinson $\mathrm{D}$, Moller $\mathrm{H}$ : Radiationinduced malignancies following radiotherapy for breast cancer. Br J Cancer 2004, 91:868-872.

25. Haffty BG: Radiation therapy and the risk of contralateral breast cancer. Int J Radiat Oncol Biol Phys 2003, 56:920-921.

26. Rothman KJ, Greenland S: Case-control studies. In Modern Epidemiology Edited by: Rothman KJ, Greenland S. Philadelphia: Lippincott-Raven; 1998:615-617.

27. Ursin G, Henderson BE, Haile RW, Pike MC, Zhou N, Diep A, Bernstein L: Does oral contraceptive use increase the risk of breast cancer in women with BRCA1/BRCA2 mutations more than in other women? Cancer Res 1997, 57:3678-3681.

28. Sambrook J, Fritsch EF, Maniatis T: Molecular Cloning: a Laboratory Manual 2nd edition. Cold Spring Harbor, New York: Cold Spring Harbor Laboratory Press; 1989.

29. LOVD [http://chromium.liacs.nl/lovd/]

30. Breslow NE, Day NE: Statistical methods in cancer research. The analysis of case-control studies. IARC Sci Publ 1980, (32):5-338.

31. Broeks A, Braaf LM, Huseinovic A, Schmidt MK, Russell NS, Van Leeuwen FE, Hogervorst FBL, van't Veer LJ: The spectrum of ATM missense variants and their contribution to contralateral breast cancer. Breast Cancer Res Treat in press. 2007, Mar 28

32. Boice JD, Land CE, Preston DL: Ionizing radiation. Cancer Epidemiology and Prevention New York: Oxford University Press edition. 1996:319-341.

33. Land CE, Tokunaga M, Koyama K, Soda M, Preston DL, Nishimori I, Tokuoka S: Incidence of female breast cancer among atomic bomb survivors, Hiroshima and Nagasaki, 1950-1990. Radiat Res 2003, 160:707-717.

34. Howe GR, McLaughlin J: Breast cancer mortality between 1950 and 1987 after exposure to fractionated moderate-dose-rate ionizing radiation in the Canadian fluoroscopy cohort study and a comparison with breast cancer mortality in the atomic bomb survivors study. Radiat Res 1996, 145:694-707.

35. Broeks A, de Witte L, Nooijen A, Huseinovic A, Klijn JG, van Leeuwen FE, Russell NS, van't Veer LJ: Excess risk for contralateral breast cancer in CHEK2*1100deIC germline mutation carriers. Breast Cancer Res Treat 2004, 83:91-93.

36. Metcalfe K, Lynch HT, Ghadirian P, Tung N, Olivotto I, Warner E, Olopade OI, Eisen A, Weber B, McLennan J, et al.: Contralateral breast cancer in BRCA1 and BRCA2 mutation carriers. J Clin Oncol 2004, 22:2328-2335.

37. Verhoog LC, Brekelmans CT, Seynaeve C, van den Bosch LM, Dahmen G, van Geel AN, Tilanus-Linthorst MM, Bartels CC, Wagner $A$, van den Ouweland $A$, et al:: Survival and tumour charac- 
teristics of breast-cancer patients with germline mutations of BRCA1. Lancet 1998, 351:316-321.

38. Verhoog LC, Brekelmans CT, Seynaeve C, Meijers-Heijboer EJ, Klijn JG: Contralateral breast cancer risk is influenced by the age at onset in BRCA1-associated breast cancer. $\mathrm{Br} J$ Cancer 2000, 83:384-386.

39. Schmidt MK, Tollenaar RA, de Kemp SR, Broeks A, Cornelisse CJ, Smit VT, Peterse JL, van Leeuwen FE, Van 't Veer LJ: Breast cancer survival and tumor characteristics in premenopausal women carrying the CHEK2*1100de/C germline mutation. J Clin Oncol 2007, 25:64-9.

40. Ronckers CM, Erdmann CA, Land CE: Radiation and breast cancer: a review of current evidence. Breast Cancer Res 2005, 7:21-32.

41. Gatti RA, Tward A, Concannon P: Cancer risk in ATM heterozygotes: a model of phenotypic and mechanistic differences between missense and truncating mutations. Mol Genet Metab 1999, 68:419-423.

42. Thorstenson YR, Roxas A, Kroiss R, Jenkins MA, Yu KM, Bachrich T, Muhr D, Wayne TL, Chu G, Davis RW, et al:: Contributions of ATM mutations to familial breast and ovarian cancer. Cancer Res 2003, 63:3325-3333.

43. Scott SP, Bendix R, Chen P, Clark R, Dork T, Lavin MF: Missense mutations but not allelic variants alter the function of ATM by dominant interference in patients with breast cancer. Proc Natl Acad Sci USA 2002, 99:925-930.

44. Fu YP, Yu JC, Cheng TC, Lou MA, Hsu GC, Wu CY, Chen ST, Wu $\mathrm{HS}$, Wu PE, Shen CY: Breast cancer risk associated with genotypic polymorphism of the nonhomologous end-joining genes: a multigenic study on cancer susceptibility. Cancer Res 2003, 63:2440-2446.

45. Bernstein JL, Langholz B, Haile RW, Bernstein L, Thomas DC, Stovall M, Malone KE, Lynch CF, Olsen JH, Anton-Culver $\mathrm{H}$, et al:: Study design: evaluating gene-environment interactions in the etiology of breast cancer - the WECARE study. Breast Cancer Res 2004, 6:R199-R214. 